\title{
Calcineurin inhibition blocks within-, but not between-session fear extinction in mice
}

\author{
Suellen Almeida-Corrêa, ${ }^{1,2}$ Thiago C. Moulin, ${ }^{1}$ Clarissa F. D. Carneiro, ${ }^{1}$ \\ Marina M. C. Gonçalves, ${ }^{1}$ Lara S. Junqueira, ${ }^{1}$ and Olavo B. Amaral ${ }^{1}$ \\ ${ }^{1}$ Institute of Medical Biochemistry Leopoldo de Meis, Federal University of Rio de Janeiro, RJ, 22290-290, Brazil
}

\begin{abstract}
Memory extinction involves the formation of a new associative memory that inhibits a previously conditioned association. Nonetheless, it could also depend on weakening of the original memory trace if extinction is assumed to have multiple components. The phosphatase calcineurin $(\mathrm{CaN})$ has been described as being involved in extinction but not in the initial consolidation of fear learning. With this in mind, we set to study whether $\mathrm{CaN}$ could have different roles in distinct components of extinction. Systemic treatment with the CaN inhibitors cyclosporin A (CsA) or FK-506, as well as i.c.v. administration of CsA, blocked within-session, but not between-session extinction or initial learning of contextual fear conditioning. Similar effects were found in multiple-session extinction of contextual fear conditioning and in auditory fear conditioning, indicating that $\mathrm{CaN}$ is involved in different types of short-term extinction. Meanwhile, inhibition of protein synthesis by cycloheximide $(\mathrm{CHX})$ treatment did not affect within-session extinction, but disrupted fear acquisition and slightly impaired between-session extinction. Our results point to a dissociation of within- and between-session extinction of fear conditioning, with the former being more dependent on $\mathrm{CaN}$ activity and the latter on protein synthesis. Moreover, the modulation of within-session extinction did not affect between-session extinction, suggesting that these components are at least partially independent.
\end{abstract}

After their consolidation, conditioned fear memories can be modified by phenomena such as extinction and reconsolidation. Even though these processes have opposite behavioral outcomes, with the former leading to fear decay, and the latter leading to its strengthening (Pavlov 1927; Nader et al. 2000), both can be modulated by similar pharmacological interventions. Protein synthesis inhibitors, for instance, may cause amnesia by blocking reconsolidation when injected after a brief reexposure to the conditioned stimulus, whereas the same drugs may preserve memory after a longer reexposure by blocking extinction (Eisenberg et al. 2003; Pedreira and Maldonado 2003; Suzuki et al. 2004).

In order to interpret these results, our group has proposed a theoretical model in which reexposure to the conditioned stimulus leads to the activation of two parallel plasticity systems, the first responsible for memory strengthening through classic consolidation pathways, and the second for labilization of existing memory traces through other molecular mechanisms (Osan et al. 2011). During reconsolidation, these systems would work in opposite directions, with the former reinforcing the original memory trace, and the latter destabilizing it. On the other hand, during memory extinction, both of them could conceivably act in concert, but on different components of the process: while consolidation mechanisms would be involved in formation of the extinction memory, the labilization system could act by transforming or weakening the original memory trace (AlmeidaCorrêa and Amaral 2014). Based on these assumptions, extinction should rely on distinct components, which could contribute differently to its behavioral outcomes in different situations (Barad 2006; Maren 2011; Riebe et al. 2012).

\footnotetext{
${ }^{2}$ Present address: Department of Stress Neurobiology and Neurogenetics, Max Planck Institute of Psychiatry, 80804 Munich, Germany Corresponding author: suellen_almeida@psych.mpg.de
} Article is online at http://www.learnmem.org/cgi/doi/10.1101//m.037770.114.
This hypothesis has recently received support from a study in which different auditory fear extinction protocols-in this case consisting of a single long tone or a series of short ones-were shown to preferentially facilitate within-session or betweensession extinction, respectively (Plendl and Wotjak 2010). Using these protocols, pharmacological blockade or genetic ablation of the CB1 receptor were shown to affect within-session extinction, but not between-session extinction (Plendl and Wotjak 2010) or initial fear conditioning (Marsicano et al. 2002). This suggests that different extinction protocols may have different molecular requirements, with the $\mathrm{CB} 1$ receptor being more important for within-session extinction than for between-session extinction. Interestingly, this receptor was also shown to be important for memory destabilization during reconsolidation (Suzuki et al. 2008; Kim et al. 2011; Lee and Flavell 2014), suggesting that it could be a part of a putative molecular system involved in the labilization of established memories during both reconsolidation and extinction (Almeida-Corrêa and Amaral 2014).

Another molecule proposed to be more important for extinction than for initial fear learning is the phosphatase calcineurin $(\mathrm{CaN})$. Animals with a forebrain-specific CaN knockout have normal reference memory in the water maze, but show impaired performance in the delayed-match-to-place version of the task (Zeng et al. 2001), indicating that CaN might be important for the modification of previously learned behavioral responses. Mice with genetic inhibition of calcineurin activity also present enhanced initial learning of some tasks (Malleret et al. 2001; Baumgärtel et al. 2008; Havekes et al. 2008; de la Fuente et al. 2014) but

(C) 2015 Almeida-Corrêa et al. This article is distributed exclusively by Cold Spring Harbor Laboratory Press for the first 12 months after the full-issue publication date (see http://learnmem.cshlp.org/site/misc/terms.xhtml). After 12 months, it is available under a Creative Commons License (AttributionNonCommercial 4.0 International), as described at http://creativecommons. org/licenses/by-nc/4.0/. 
impaired extinction of taste and contextual fear conditioning (Baumgärtel et al. 2008; Havekes et al. 2008). Moreover, CaN activity in the amygdala seems to be unaltered (Lin et al. 2003a) or repressed during initial learning (Baumgärtel et al. 2008), but both its activity (Lin et al. 2003a) and protein content (Merlo et al. 2014) in the amygdala and its nuclear content in the hippocampus (de la Fuente et al. 2011) are increased after extinction. Finally, blockade of calcineurin activity in the hippocampus (de la Fuente et al. 2011) or of its expression in the amygdala (Merlo et al. 2014) can disrupt extinction of fear conditioning, and its inhibition in the amygdala interferes with memory destabilization during reconsolidation of an inhibitory avoidance memory (Fukushima et al. 2014). Taken together, these results suggest that CaN seems to be more involved in labilization of an existing memory trace than in formation of a fear memory.

Since such a profile is consistent with what has been described for the CB1 receptor (Marsicano et al. 2002; AlmeidaCorrêa and Amaral 2014), it is possible that CaN might also have distinct effects on different components of memory extinction-for example, in within- and between-session extinction. Such a demonstration would be important in terms of describing a set of molecular mechanisms specifically involved in shortterm extinction, and for supporting the idea that different components of extinction depend on parallel and partly independent plasticity systems. With this in mind, we studied the outcomes of calcineurin inhibition on different fear extinction protocols, focusing on possible dissociations between its short- and longterm effects.

\section{Results}

\section{CaN inhibition does not affect the formation}

\section{of contextual fear memory}

It is widely described that protein synthesis plays a key role in the establishment of a new memory (Hernandez and Abel 2008). In order to validate our contextual fear-conditioning protocol in Swiss Webster mice, thus, we injected the protein synthesis inhibitor cycloheximide (CHX, $100 \mathrm{mg} / \mathrm{kg}$, i.p.) $30 \mathrm{~min}$ before a fear conditioning session, consisting of $3 \mathrm{~min}$ in the context in which animals received a pair of $0.8 \mathrm{~mA}$ footshocks. As expected, protein synthesis inhibition during training impaired freezing responses measured in a test $24 \mathrm{~h}$ later (Fig. 1A, $n=15-18$; Student's $t$ test, $P=0.003)$. On the contrary, injection of the CaN activity inhibitor cyclosporin A (CsA, $20 \mathrm{mg} / \mathrm{kg}$, i.p.), 60 min before training did not influence formation of the conditioned memory, as tested either $24 \mathrm{~h}$ (Fig. 1B, $n=15-16$; Student's $t$ test, $P=0.43$ ) or $30 \mathrm{~min}$ after the conditioning session $(n=11-13$; Student's $t$ test, $P=0.49$ ) in different animals (Fig. $1 \mathrm{C})$. These results indicate that, unlike protein synthesis, CaN does not seem to play a major role in the initial learning of contextual fear conditioning.

\section{Systemic CaN inhibition blocks within-session, but not between-session contextual fear extinction}

In order to evaluate the effects of inhibiting CaN activity on the extinction of contextual fear memory, we first trained the animals on a conditioning protocol similar to the one used in the previous experiment. Twenty-four hours after training, mice were injected with CsA ( $20 \mathrm{mg} / \mathrm{kg}$; i.p.) or its vehicle (DMSO) $60 \mathrm{~min}$ before an extinction session, which consisted of a 30-min reexposure to the conditioning context in the absence of shock. Twenty-four hours after the extinction session, the animals were tested in the same context for 3 min (Fig. 2A).

Although both groups showed similar levels of freezing at the beginning of the extinction session, animals in the control group showed a gradual decrease in freezing along this session, while animals treated with CsA showed a slight increase in freezing (Fig. 2B, $n=21-22$; data from two pooled experiments; two-way repeated-measures ANOVA; $P($ drug $)=0.001 ; P($ time $)=0.16 ; P$ (interaction) $=0.0004)$, indicating that the blockade of CaN prevented within-session extinction. When tested $24 \mathrm{~h}$ later, however, animals of both groups decreased their levels of freezing in comparison to the beginning of the extinction session (two-way repeated-measures ANOVA; $P($ drug $)=0.30 ; P($ time $)<0.001 ; P$ (interaction) $=0.73$ ) and did not differ significantly from each other (Student's $t$ test with Welch's correction, $P=0.20$ ), suggesting that $\mathrm{CaN}$ did not have a significant effect on long-term (between-session) extinction.

Given that CsA inhibits CaN through an indirect mechanism, by forming a complex with cyclophilin (CyP) (Huai et al.
A
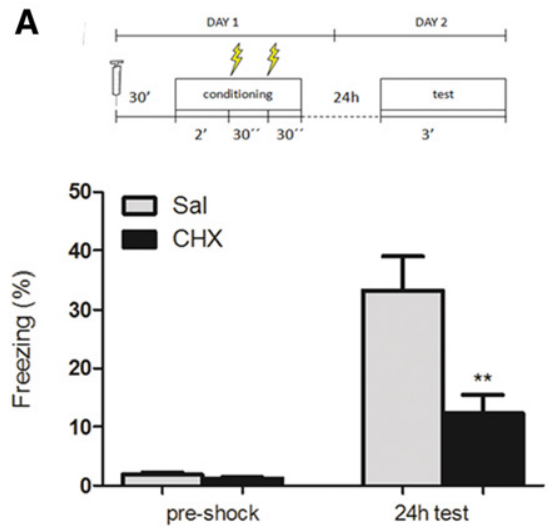

B
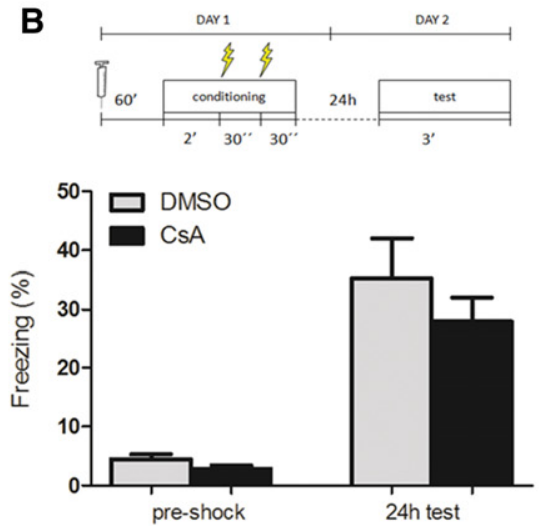

C
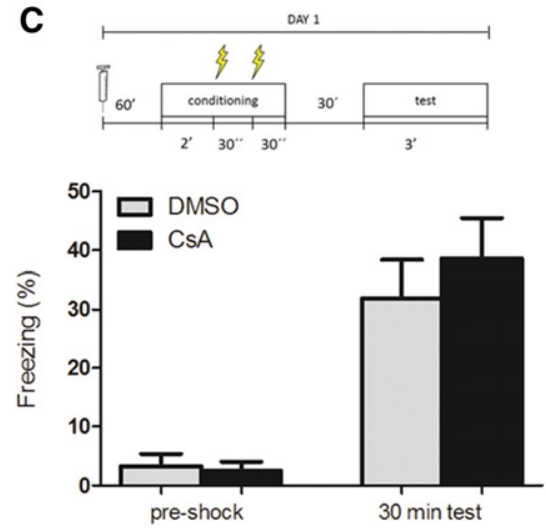

Figure 1. CsA does not affect initial learning of contextual fear conditioning. ( $A$ ) Mean time spent freezing (\%) ( \pm SEM) by mice treated with CHX $(100 \mathrm{mg} / \mathrm{kg})$ or saline $30 \mathrm{~min}$ before the conditioning session, during the preshock period of the training session (preshock) and during the test session $24 \mathrm{~h}$ later, showing a significant effect of the drug on memory formation $(n=15$ (CHX), 18 (DMSO); Student's $t$ test, $P=0.003) ;(* *) P<$ 0.01. (B) Mean time spent freezing by mice treated with CsA (20 mg/kg) or vehicle (DMSO) $60 \mathrm{~min}$ before the conditioning session, during the preshock period of the training session and during the test session $24 \mathrm{~h}$ later. There was no significant difference in freezing between groups ( $n=16$ (CsA), 15 (DMSO); Student's $t$ test, $P=0.43) ;(C)$ Mean time spent freezing by mice treated with CsA or vehicle as in $B$, but with the test session performed $30 \mathrm{~min}$ after the end of training. There was no significant difference in freezing between groups ( $n=11$ (CsA), 13 (DMSO); Student's $t$ test, $P=0.49)$. 


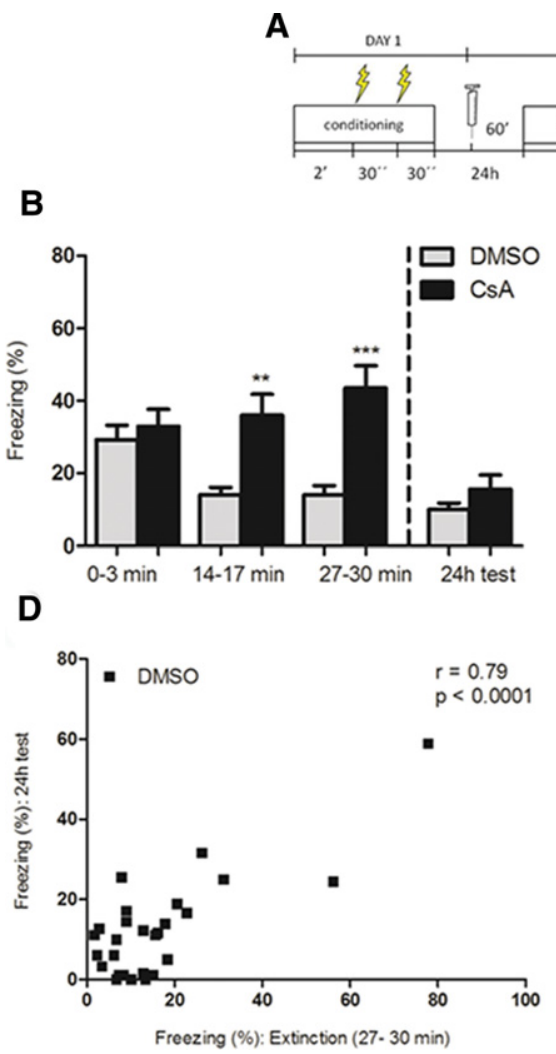

DAY2 DAY3

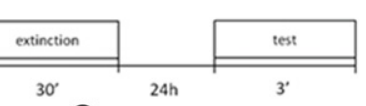

C

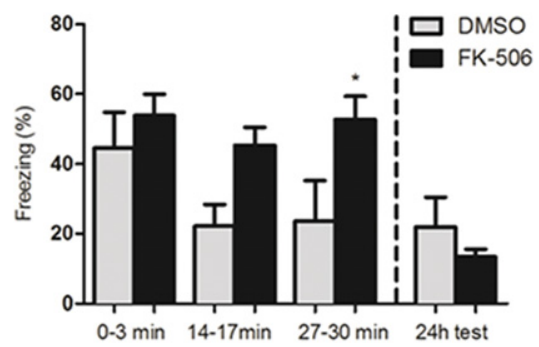

E

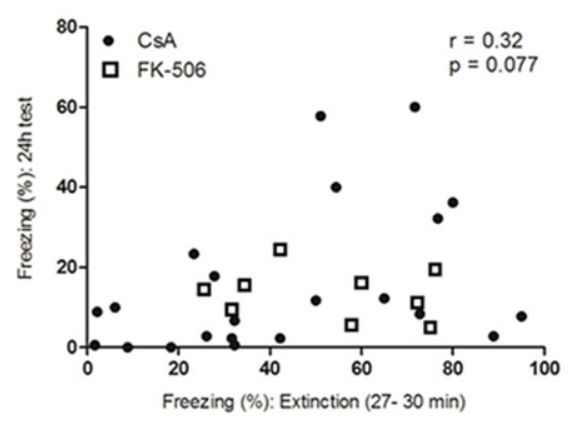

Figure 2. CSA and FK-506 block within-session but not between-session extinction of contextual fear conditioning. (A) Schematic representation of the protocol used in the experiments. (B) Mean time spent freezing $(\%)( \pm$ SEM) by mice treated with CsA $(20 \mathrm{mg} / \mathrm{kg})$ or vehicle (DMSO) 60 min before a 30-min extinction session, with bars representing early (0-3 min), intermediate (14-17 min), and late (27$30 \mathrm{~min}$ ) periods of this session, as well as a drug-free test $24 \mathrm{~h}$ later. CsA blocked within-session extinction $(n=22$ (CsA), 21 (DMSO), data from two pooled experiments; two-way repeated-measures ANOVA; $P$ (drug) $=0.001 ; P$ (time) $=0.16 ; P$ (interaction) $\left.=0.0004 ;\left(^{* *}\right) P<0.01,{ }^{* * *}\right) P<0.001$, Bonferroni post hoc test), but not between-session extinction (two-way repeated-measures ANOVA between initial 3 min of the extinction session and the test session; $P$ (drug) $=0.30 ; P$ (time) $<0.0001 ; P$ (interaction) $=0.73$; Student's $t$ test with Welch's correction for group comparison in the test session, $P=0.20)$. (C) Mean time spent freezing by mice treated with FK-506 $(5 \mathrm{mg} / \mathrm{kg})$ or vehicle (DMSO) $60 \mathrm{~min}$ before the extinction session, using the same protocol as in $B$. FK-506 blocked within-session extinction $(n=9$ (FK-506), 6 (DMSO), two-way repeated-measures ANOVA, $P$ (drug) $=0.02 ; P($ time $)=$ $0.07, P$ (interaction) $=0.30 ;\left(^{*}\right) P<0.05$, Bonferroni post hoc test), but not between-session extinction (two-way repeated-measures ANOVA between initial $3 \mathrm{~min}$ of the extinction session and the test session $24 \mathrm{~h}$ after; $P($ drug $)=0.96 ; P$ (time $)<0.0001 ; P$ (interaction $)=0.07$; Student's $t$ test with Welch's correction for group comparison in the test session, $P=0.38)$. $(D)$ Correlation between freezing levels $(\%)$ of control mice during the final 3 min of the extinction session (within-session extinction) and during the test session $24 \mathrm{~h}$ later (between-session extinction). A significant correlation was observed $(n=27 ; r=$ $0.79 ; \quad P<0.0001)$, mostly due to animals showing high-freezing levels in both sessions. (E) Correlation between freezing levels (\%) ( \pm SEM) of mice treated with CsA ( $20 \mathrm{mg} / \mathrm{kg}$, black dots) or FK-506 (5 mg/kg, white squares) during the final $3 \mathrm{~min}$ of the extinction session and during the test session $24 \mathrm{~h}$ later, indicating a nonsignificant trend for a weak correlation between these values (Fig. $2 \mathrm{E} ; n=31 ; r=0.32 ; P=0.07)$.

2002), we sought to validate this result with the injection of another CaN inhibitor, FK-506 (5 mg/kg, i.p.). Similar effects were obtained with this drug, with differences in freezing observed between groups at the end of the extinction session (Fig. 2C, $n=6-$ 9; two-way repeated-measures ANOVA; $P($ drug $)=0.02 ; P($ time $)=$ $0.07 ; P($ interaction $)=0.30)$. Once more, both groups showed decreased freezing $24 \mathrm{~h}$ later (two-way repeated-measures ANOVA; $P($ drug $)=0.96 ; P($ time $)<0.0001 ; P($ interaction $)=0.07)$ with no difference between them in the test session (Student's $t$ test with Welch correction, $P=0.38$ ), corroborating the hypothesis that $\mathrm{CaN}$ seems to play a role in the rapid decrease of the fear response during the extinction session, but not in the formation of a long-term extinction memory.
The distinct effects of CaN inhibition on short- and long-term extinction point to a possible dissociation and independence of these different components of extinction. To further investigate this possibility, we tested if there was a correlation between freezing levels at the end of the extinction session and in the test session on the following day among individual animals. When analyzing animals in the control group, a correlation between freezing during the last $3 \mathrm{~min}$ of the extinction session and freezing during the $24 \mathrm{~h}$ test was found (Fig. 2D; $n=27 ; r=0.79 ; P<0.0001)$. When considering animals treated with either CsA or FK-506, on the other hand, this correlation was not significant (Fig. 2E; $n=$ $31 ; r=0.32 ; P=0.07)$. Note that the high correlation found among control animals was mainly due to animals showing high baseline freezing and a small degree of extinction-if only animals displaying freezing levels up to \pm 1 $\mathrm{SD}$ from the mean during the initial 3 min of the extinction session are considered (thus ensuring similar baseline freezing levels among animals), the correlation is much more modest in controls $(n=15 ; \quad r=0.57 ; \quad P=0.027$; data not shown), and remains nonsignificant in treated animals $(n=21, r=0.35, P=$ 0.12 ; data not shown). This suggests that, although they are partly correlated in control animals, within- and betweensession extinction can occur independently of each other in some cases, as when $\mathrm{CaN}$ is inhibited.

\section{Intracerebroventricular (i.c.v.) injection of CsA also blocks within-session extinction}

To confirm that the effects on freezing observed with systemic injection of CsA were due to its effects in the brain, we repeated the experiment described above, but this time administering the drug (15 $\mu \mathrm{g} / \mu \mathrm{L}, 2 \mu \mathrm{L} /$ mouse), or its vehicle (DMSO 85\%, $2 \mu \mathrm{L}$ ) via intracerebroventricular (i.c.v.), free-hand injection (Fig. 3A). The outcomes of CsA i.c.v. injection were similar to the results found with systemic CsA injections, with a decrease in freezing observed in controls but not in animals treated with CsA over the 30-min extinction session (Fig. 3B, $n=7-8$; two-way repeated-measures ANOVA; $P($ drug $)=0.04 ; P($ time $)=0.001 ; P($ interaction $)=$ 0.08 ). Again, both groups showed extinction from one day to the next (two-way repeated-measures ANOVA between initial 3 min of extinction and test session; $P($ drug $)=0.49 ; P($ time $)<0.0001$; $P($ interaction $)=0.72$ ), with no significant difference in freezing between groups in the test session (Student's $t$ test, $P=0.57$ ).

On the contrary, CHX injection ( $55 \mu \mathrm{g} / 3 \mu \mathrm{L} /$ mouse) did not significantly affect within-session extinction, with both groups showing a decrease in freezing levels over this session (Fig. 3C, $n=8-9$; two-way repeated-measures ANOVA; $P(\operatorname{drug})=0.32 ; P$ 
A

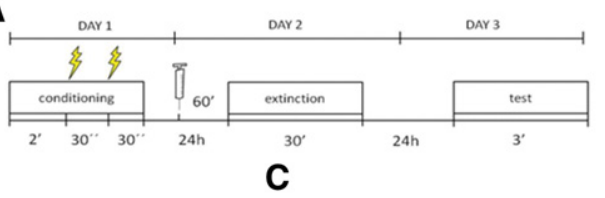

B

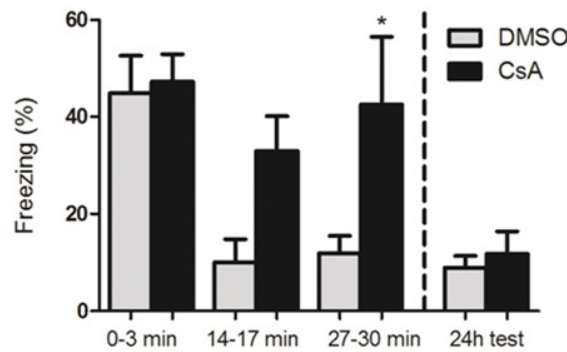

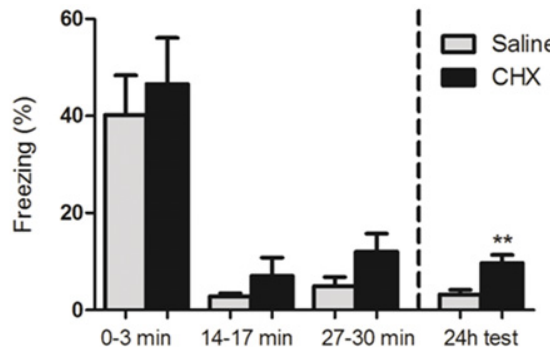

Figure 3. I.c.v. injections of $\mathrm{CsA}$ and $\mathrm{CHX}$ affect different components of contextual fear extinction. (A) Schematic representation of the protocol used in the experiments. (B) Mean time spent freezing (\%) ( \pm SEM) by mice treated with CsA $(2 \mu \mathrm{L}, 15 \mathrm{mg} / \mu \mathrm{L}$ ) or vehicle (DMSO $85 \%) 60 \mathrm{~min}$ before a $30-\mathrm{min}$ extinction session, showing within-session extinction impairment in CsA-treated animals ( $n=7$ (CsA), 8 (DMSO); two-way repeated-measures ANOVA; $P($ drug $)=0.04 ; P($ time $)=0.001 ; P$ (interaction = $0.08 ;\left(^{*}\right) P<0.05$, Bonferroni post hoc test) and no effect on the test session $24 \mathrm{~h}$ later (two-way repeated-measures ANOVA between initial $3 \mathrm{~min}$ of the extinction session and the test session; $P($ drug $)=0.49 ; P$ (time $)<0.0001 ; P$ (interaction) $=0.72$; Student's $t$ test for group comparison in the test session, $P=0.57)$. (C) Mean time spent freezing by mice treated with $\mathrm{CHX}(55 \mu \mathrm{g} / 3 \mu \mathrm{L} /$ mouse) or vehicle (saline) $60 \mathrm{~min}$ before a 30 -min extinction session, showing no significant effect of treatment on within-session extinction $(n=8(\mathrm{CHX}), 9$ (saline); two-way repeated-measures ANOVA; $P($ drug $)=0.32 ; P($ time $)<0.0001 ; P$ (interaction $)=0.95)$, and a slight difference between groups during the test session $24 \mathrm{~h}$ later (Student's $t$ test, $P=0.003,\left({ }^{*}\right) P<0.01$ ), even though betweensession extinction still occurred in both groups (two-way repeated-measures ANOVA between initial $3 \mathrm{~min}$ of the extinction session and the test session; $P$ (drug) $=0.29 ; \quad P$ (time) $<0.0001 ; P$ $($ interaction $)=0.99$ )

$($ time $)<0.0001 ; P($ interaction $)=0.95)$. Both groups also showed a decrease in freezing levels between the beginning of the extinction session and the test session (two-way repeated-measures ANOVA; two-way repeated-measures ANOVA; $P($ drug $)=0.29 ; P$ (time) $<0.0001 ; P$ (interaction $)=0.99$ ); however, there was a small but significant difference between groups in the $24 \mathrm{~h}$ test (Student's $t$ test, $P=0.003$ ), indicating a slight impairment of between-session extinction by CHX. Nevertheless, the fact that both groups present a significant decrease in freezing from $1 \mathrm{~d}$ to the next suggests that some degree of extinction can occur even when protein synthesis is inhibited.

\section{Within-session effects of $\mathrm{CaN}$ inhibition are also observed in multiple-session contextual fear extinction}

To analyze whether the effects observed with CaN inhibition during a single 30-min session would also occur in multiple-session extinction, we used a similar contextual fear conditioning protocol as the one described above, but divided extinction in either daily 5 -min sessions over $6 \mathrm{~d}$ or daily 10-min sessions over $3 \mathrm{~d}$, injecting animals with systemic CsA $(20 \mathrm{mg} / \mathrm{kg})$ or DMSO before each session. Sessions began $24 \mathrm{~h}$ after conditioning, were spaced $24 \mathrm{~h}$ apart, and were followed by a drug-free test session $24 \mathrm{~h}$ after the last extinction session. No significant differences were observed between groups during the initial $3 \mathrm{~min}$ of the extinction sessions in either protocol (Fig. 4A,B; two-way repeated-measures ANOVA, $n=11-12, P($ drug $)=0.76 ; P$ (time) $=0.33 ; P$ $($ interaction $)=0.18$ for 5 - $\min$ sessions; $n=5-7, P($ drug $)=0.70$, $P$ (time) $=0.03, P$ (interaction $)=0.27$ for $10-\min$ sessions $)$. However, when the final minutes of the sessions $(2 \mathrm{~min}$ for 5-min sessions, $3 \mathrm{~min}$ for 10-min sessions) were analyzed across days, a significant drug effect was observed, with treated animals showing increased levels of freezing at the end of the sessions (two-way repeated-measures ANOVA, $P($ drug $)=0.009 ; \quad P$ (time $)=$ $0.27 ; P$ (interaction $)=0.67$ for 5 -min sessions; $P($ drug $)=0.0002, P($ time $)=0.02$, $P($ interaction $)=0.24)$.

Between-session extinction was much more robust in the daily 10-min session protocol than in the 5-min session one (as shown by the time effects in the ANOVA results); still, when the first $3 \mathrm{~min}$ of the first extinction session were compared with the drug-free test session, a significant effect of time was observed in both protocols (two-way repeated-measures ANOVA $P($ drug $)=$ $0.82 ; P($ time $)=0.0005 ; P($ interaction $)=$ 0.33 for 5 -min sessions; $P($ drug $)=0.95 ; P$ $($ time $)=0.002 ; P$ (interaction $)=0.73$ for 10-min sessions). Again, no difference between groups was found in the test day in either protocol (Student's $t$ test, $P=0.68$ for 5 -min sessions, $P=0.71$ for 10 -min sessions), suggesting that $\mathrm{CaN}$ blockade did not affect long-term extinction on either protocol, despite its effect on within-session extinction. We note that the comparison between different intervals in each session had not been planned a priori for the 5 -min sessions, but became a relevant exploratory analysis to perform after the striking effects of CsA on within-session extinction were observed in the single-session protocol.

\section{CaN inhibition blocks within-session auditory fear extinction}

Contextual and cued fear conditioning are known to have different neurobiological requirements, with cued fear conditioning being less dependent on the hippocampus for its formation and retrieval (Kim and Fanselow 1992). For this reason, we also tested the effect of systemic CaN inhibition in an auditory fear extinction protocol. Animals were initially conditioned with three tones $(100 \mathrm{~dB}, 1 \mathrm{kHz}, 20 \mathrm{sec} /$ each) paired with 0.6-mA, 2-sec footshocks. Twenty-four hours later, they were injected with CsA $(20 \mathrm{mg} / \mathrm{kg}$, i.p.), or DMSO 60 min before an extinction session, which consisted of exposure to a 180-sec tone in a novel context (Fig. 5A), a procedure previously shown to maximize within-session extinction (Plendl and Wotjak 2010). Similarly to what was observed in contextual fear conditioning, animals in the control group showed a greater decrease in freezing levels over the extinction session than those injected with CsA (Fig. $5 \mathrm{~B}, n=8$ /group; two-way repeated-measures ANOVA, $P($ drug $)=0.02 ; P$ (time $)=0.004 ; P$ (interaction) $=0.47$ ). In a test session $24 \mathrm{~h}$ later, no difference was observed between groups when average freezing levels over three 20-sec tones were measured (Student's $t$ test, $P=0.61$ ), with both groups showing a slight decrease in freezing compared with the first $60 \mathrm{sec}$ of the extinction session (two-way repeatedmeasures ANOVA, $P$ (drug) $=0.42, P$ (time) $<0.0001, P$ (interaction $)=0.40$ ). The small (albeit significant) degree of betweensession extinction is actually expected from the single-tone procedure used (Plendl and Wotjak 2010)—we note, however, that the long 60 -sec continuous tone in the beginning of the extinction 
A
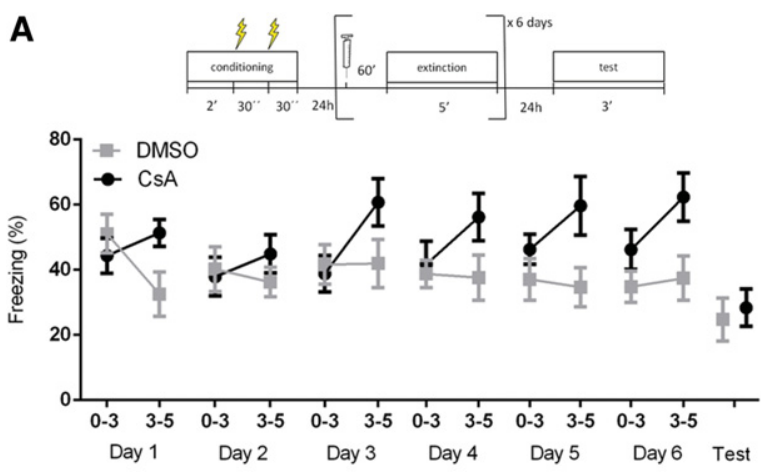

B
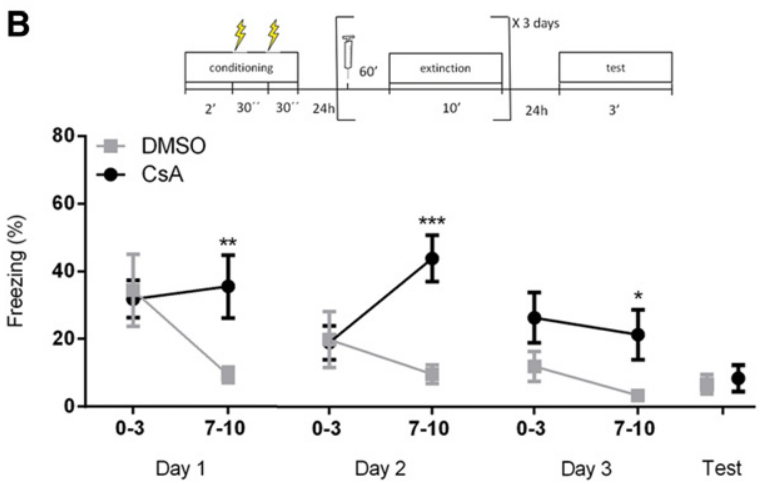

Figure 4. CsA impairs within-session extinction of contextual fear conditioning over multiple sessions. $(A)$ Schematic representation of the protocol and mean time spent freezing (\%) ( \pm SEM) of mice treated with CsA (20 mg/kg) or vehicle (DMSO) 60 min prior to six daily 5-min extinction sessions. Line graphs show freezing levels for the first $3 \mathrm{~min}$ and the last 2 min of the session for each day of extinction, as well as for the 3 min of the test session. No difference between groups is found during the initial $3 \mathrm{~min}$ of the extinction sessions $(n=11$ (CsA), 12 (DMSO); two-way repeated-measures ANOVA, $P$ (drug) $=0.76, P$ (time) $=0.33$, $P$ (interaction) $=0.18$ ). However, a significant difference is observed in the final $2 \mathrm{~min}$ of the sessions (two-way repeated-measures ANOVA, $P$ $($ drug $)=0.009, P($ time $)=0.27, P$ (interaction $)=0.67)$. Both groups show a similar degree of extinction when the initial $3 \mathrm{~min}$ of the first session are compared with the drug-free test session (two-way repeated-measures ANOVA; $P$ (drug) $=0.82 ; \quad P$ (time) $=0.0005 ; \quad P$ (interaction) $=0.33$; Student's $t$ test for group comparison in the test session, $P=0.68)$. (B) Schematic representation of the protocol and mean time spent freezing (\%) ( \pm SEM) of mice treated with CSA $(20 \mathrm{mg} / \mathrm{kg}$ ) or vehicle (DMSO) $60 \mathrm{~min}$ prior to three daily 10 -min extinction sessions. Line graphs show freezing levels for the first 3 min and the last $3 \mathrm{~min}$ of the session for each day of extinction, as well as for the 3 min of the test session. No difference between groups is observed during the initial $3 \mathrm{~min}$ of the extinction sessions, with a significant effect of time showing that extinction occurs over days ( $n=5$ (CsA), 7 (DMSO); two-way repeated-measures ANOVA, $P$ (drug) $=0.70, P$ $($ time $)=0.04, P$ (interaction $)=0.27)$. At the end of the sessions, however, large differences in freezing are observed between the groups (two-way repeated-measures ANOVA, $P$ (drug) $=0.0002, P$ (time) $=$ $0.02, P$ (interaction) $=0.23 ;\left(^{*}\right) P<0.05,\left({ }^{* *}\right) P<0.01,\left({ }^{* * *}\right) P<0.001$, Bonferroni post hoc test). Both groups show similarly robust extinction when the initial 3 min of the first session are compared with the drug-free test session (two-way repeated-measures ANOVA; $P($ drug $)=0.96 ; P$ $($ time $)=0.002 ; P$ (interaction $)=0.73$; Student's $t$ test for group comparison in the test session, $P=0.71)$.

session might not be fully comparable to the three 20 -sec tones used in the test session.

To address this issue, we also used a different extinction protocol using 30 nonreinforced 20 -sec tones with variable intervals, which allows comparison with the test session and causes more robust extinction across days (Plendl and Wotjak 2010). Strikingly, we found that this protocol did not induce withinsession extinction in either group-on the contrary, freezing levels in response to the tones actually increased slightly throughout the session (Fig. 5C, two-way repeated-measures ANOVA, $P \quad($ drug $)=0.88, \quad P \quad($ time $)=0.0002, \quad P \quad($ interaction $)=0.51)$.

A
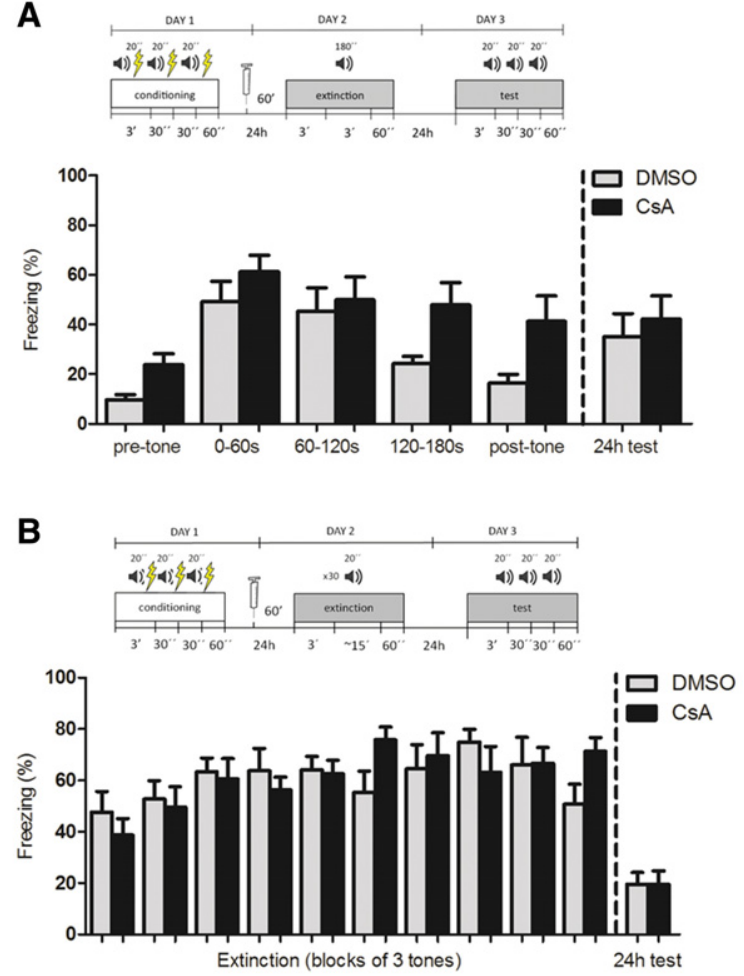

Figure 5. CsA impairs within-session but not between-session extinction of auditory fear conditioning. $(A)$ Schematic representation of the protocol and mean time spent freezing (\%) ( \pm SEM) of mice treated with CsA $(20 \mathrm{mg} / \mathrm{kg})$ or vehicle (DMSO) $60 \mathrm{~min}$ before an extinction session consisting of a single 3-min tone. Bars on the right of the left line show freezing during the $3-\mathrm{min}$ pretone period, the early (0$60 \mathrm{sec})$, medium $(60-120 \mathrm{sec})$ and late $(120-180 \mathrm{sec})$ periods of the tone, and 1-min period after the tone, showing increased freezing of the CsA-treated animals compared with controls toward the end of the session ( $n=8 /$ group, two-way repeated-measures ANOVA, $P$ (drug) $=$ $0.02, P$ (time) $=0.004, P$ (interaction) $=0.47$ ). Bars on the right of the dashed line show mean freezing time for the three 20 -sec tones in the test session $24 \mathrm{~h}$ later, with both groups showing a similarly small, albeit significant, decrease in freezing between the first minute of the extinction session and the test session average ( $n=10$ /group, two-way repeated-measures ANOVA, $P$ (drug) $=0.42, P$ (time) $<0.0001, P$ (interaction) $=0.40$; Student's $t$ test for group comparison in the test session, $P=0.61)$. (B) Schematic representation of the protocol and mean time spent freezing (\%) $( \pm$ SEM) of mice treated with CsA $(20 \mathrm{mg} / \mathrm{kg}$ ) or vehicle (DMSO) 60 min before an extinction session consisting of thirty 20 -sec tone presentations, with a variable interval of 5$20 \mathrm{sec}$. Bars on the left side of the dashed line show freezing during the 30 tones, grouped in 3-tone blocks, with no difference in freezing between CsA-treated and control animals and absence of extinction during this session for both groups ( $n=10$ /group, two-way repeatedmeasures ANOVA, $P$ (drug) $=0.88, P$ (time $)=0.0002, P$ (interaction) $=$ $0.05)$. Bars on the right of the dashed line show mean freezing time for the three 20 -sec tones in the test session $24 \mathrm{~h}$ later, indicating significant between-session extinction in both groups, with no difference between them in the test session ( $n=10 /$ group, two-way repeated-measures ANOVA between first three tones of extinction and test, $P$ (drug) $=$ $0.58, P$ (time) $<0.0001, P$ (interaction) $=0.23$; Student's $t$ test for group comparison in the test session, $P=0.98$ ). 
Nevertheless, both groups showed a clear decrease in freezing across days (two-way repeated-measures ANOVA, $P$ (drug) $=$ $0.58, P($ time $)<0.0001, P($ interaction $)=0.23)$. Interestingly, no effect of CsA was observed on either within- or between-session freezing levels. This experiment demonstrates that within-session and between-session extinction can occur largely independently of each other, and suggests that the effect of CsA on auditory fear conditioning is restricted to protocols in which withinsession extinction can be observed.

\section{CsA does not cause nonspecific modulation of anxiety or locomotion levels}

Since all of the effects of $\mathrm{CaN}$ inhibition were observed with preextinction injections, it could be argued that the results could be related not to memory extinction, but to nonspecific modulation of anxiety and/or locomotion levels (Von Hörsten et al. 1998). However, injection of CsA (20 mg/kg) had no effect on anxiety levels in the elevated plus maze, measured either by time spent in the open arms (Fig. 6A), or by the number of open arm entries (Fig. 6B) $(n=12 /$ group; Student's $t$ test, $P=0.61$ for time, $P=$ 0.47 for entries). Concerning locomotion, CsA injection led to a slight but significant increase in average distance traveled in a 10-min open field session (Fig. 6C; $n=20-21$, data from two pooled experiments; two-way repeated-measures ANOVA, $P$
$($ drug $)=0.02, P($ time $)<0.0001, P($ interaction $)=0.95)$. This also argues against a nonspecific modulation of freezing by CsA in the extinction experiments, as from the locomotor effects observed one would expect a slight decrease in this behavior, and not an increase, as observed in the extinction experiments.

As a last control to address the possibility that a nonspecific effect of CsA on freezing levels might occur in conditioned animals, we trained animals in the same contextual fear-conditioning protocol used in the previous experiments, and $24 \mathrm{~h}$ later placed the animals for $30 \mathrm{~min}$ in a different context. In this case, freezing levels were low in the beginning of the session; nevertheless, immobility levels actually increased throughout the session, not due to increased freezing but rather due to a large percentage of animals showing sleep-like behavior after some time of exploration (Fig. 6D). No significant effect of CsA was observed in this case (two-way repeated-measures ANOVA, $P($ drug $)=0.18 ; P$ (time $)<0.0001, P$ (interaction $)=$ 0.92 ), and although immobility levels were slightly (and nonsignificantly) higher in the CsA group, we note that the large sample size used in this experiment provided us with a power of $97 \%$ to detect a difference between groups as large as that observed in Figure 2B. This suggests that, even if there was a slight effect of CsA on immobility, it is highly unlikely that it could account for the results observed in the single-session extinction experiments.
A

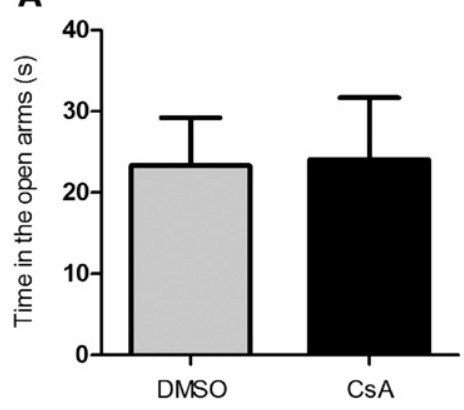

C

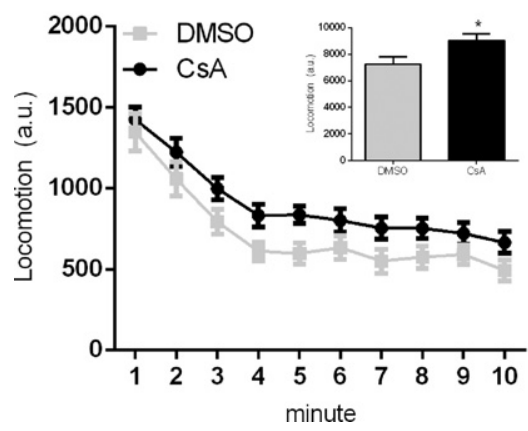

B

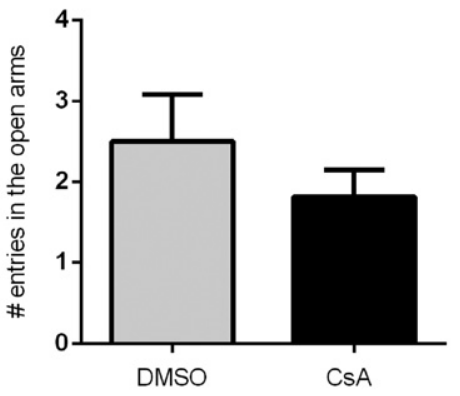

D

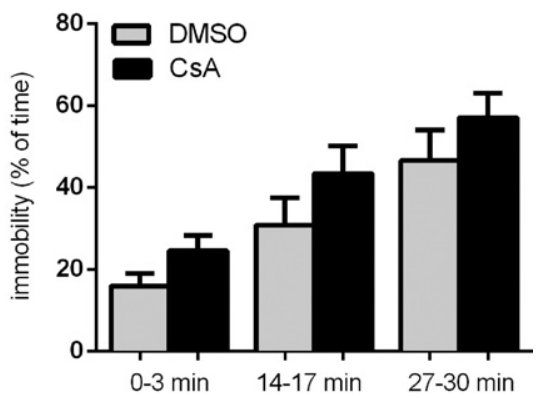

Figure 6. Effects of CsA on elevated plus maze performance, open field exploration and immobility in a novel context after fear conditioning. Mean \pm SEM of $(A)$ time $(n=12 /$ group; Student's $t$ test, $P=0.61)$ and $(B)$ number of entries (Student's $t$ test, $P=0.47$ ) in the open arms of the elevated plus-maze over 5 min by animals treated with CsA $(20 \mathrm{mg} / \mathrm{kg})$ or vehicle (DMSO) 60 min before the task. (C) Locomotion (mean \pm SEM) of mice during the 10-min open field exploration session, measured in arbitrary units ( $n=21$ (CsA), 20 (DMSO), two pooled experiments; two-way repeated-measures ANOVA, $P$ $($ drug $)=0.02, P$ (time) $<0.0001, P$ (interaction $)=0.95)$. Inset shows mean \pm SEM of the pooled locomotion in each group of animals over the whole session (Student's $t$ test, $P=0.02$ ); $\left({ }^{*}\right) P<0.05$. (D) Mean time (\%) $( \pm$ SEM) of time spent in immobility of fear-conditioned mice treated with CsA $(20 \mathrm{mg} / \mathrm{kg}$ ) or vehicle (DMSO) $60 \mathrm{~min}$ before a 30-min session in a novel context (different from the conditioning one). 3-min bins represent early (0-3 min), intermediate (14-17 min), and late (27-30 min) periods of this session. Both groups show an increase in immobility over time, mostly due to sleep activity, with no significant difference between groups (three pooled experiments, $n=28$ (CsA), 25 (DMSO); two-way repeated-measures ANOVA; $P($ drug $)=0.11 ; P($ time $)<0.0001 ; P$ (interaction $)=0.79)$.

\section{Discussion}

Based on the results presented here, we suggest that memory extinction seems to depend on two distinct components: one involved in the rapid adaptation of behavior during the extinction session and another involved with the formation of a long-term extinction memory. Inhibition of CaN activity affects the withinsession component of extinction, but not the between-session one, and this effect on the short-term does not influence the long-term consolidation of extinction, at least in the protocols we have used. Remarkably, this seems to occur in various forms of memory extinction, including single-session and multiplesession contextual extinction and singletone auditory extinction, and with both systemic and central injections.

On the other hand, calcineurin inhibition does not seem to affect the initial consolidation of contextual fear conditioning, as tested either $30 \mathrm{~min}$ or $24 \mathrm{~h}$ later. On this matter, conflicting results have been reported using different paradigms, with some studies showing facilitation of conditioning by FK-506 (de la Fuente et al. 2014), antisense DNA against genes coding for the catalytic subunits of CaN (Ikegami and Inokuchi 2000), and transgenic inhibition of CaN (Malleret et al. 2001; Baumgärtel et al. 2008; Havekes et al. 2008) and others finding no effect of the latter intervention (Zeng et al. 2001). Still, in accordance with our results, most of these studies have found that the transgenic (Baumgärtel et al. 2008; Havekes 
et al. 2008), pharmacological (de la Fuente et al. 2011), or transcriptional (Merlo et al. 2014) inhibition of calcineurin impairs various aspects of memory extinction.

It should be noted that, unlike what occurred in our study, some of these previous investigations (de la Fuente et al. 2011; Merlo et al. 2014) did find an effect of calcineurin inhibition on long-term extinction. This disparity could be due to methodological differences such as different animal species or strains, different behavioral protocols, or different sites of CaN inhibition. In these previous studies, which used inbred C57BL/6 mice (de la Fuente et al. 2011) and rats (Merlo et al. 2014), animals were trained in an auditory fear conditioning paradigm, even though they were tested for contextual fear conditioning in de la Fuente et al. (2011). Furthermore, in these studies CaN was inhibited locally in the hippocampus by FK-506 (de la Fuente et al. 2011) or in the amygdala by an antisense oligodeoxynucleotide (Merlo et al. 2014), a fact that might also account for the observed disparities.

The different effects of $\mathrm{CaN}$ on within- and between-session extinction in our experiments, as well as the observation that the latter can be induced in the absence of the former, suggest a possible dissociation between these two components. This temporal dissociation of extinction is analog to that of memory consolidation, in which it is possible to identify two distinct, and to a certain point independent, phases of memory processing and formation (Izquierdo et al. 1998). Importantly, a recent study demonstrated a similar dissociation of auditory fear extinction into two distinct components (defined by the authors as "fear relief" and "relearning") by manipulating the CB1 receptor (Plendl and Wotjak 2010). Our study extends this result to contextual fear conditioning and adds a second molecular component to the within-session/fear relief system responsible for the rapid labilization of conditioned responses.

On the other hand, between-session extinction or "relearning" seems to depend more on processes that are also important for the initial consolidation of memory, such as protein synthesis (Suzuki et al. 2004), activation of NMDA receptors (Szapiro et al. 2003; Davis 2011) and others. In our study, protein synthesis inhibition did not cause a significant impairment in short-term extinction of contextual fear conditioning, but a significant difference was observed on freezing levels on the test $24 \mathrm{~h}$ later. Nevertheless, although there was a slight effect of protein synthesis inhibition on long-term extinction, levels of freezing were still much lower in the test session when compared with the beginning of the extinction session, suggesting that some degree of extinction can happen without protein synthesis, as shown in other studies (Lattal and Abel 2001; Lattal et al. 2004). An alternative interpretation for these results would be that CHX treatment was not sufficient to inhibit protein synthesis to a level that would completely block extinction. One way or another, this result highlights once more the dissociation of extinction into two components that seem to depend on distinct biochemical pathways.

Concerning the specificity of the pharmacological effects we describe, it is known that CsA acts by binding to cyclophilins, forming a CaN-inhibiting complex, while FK-506 forms a similarly acting complex with FK-506 binding protein (FKBP) (Liu et al. 1991; Schreiber 1991; Bram et al. 1993; Kissinger et al. 1995; Huai et al. 2002). It is possible that interference with these targets, rather than CaN inhibition, could underlie the observed behavioral effects, as both cyclophilin D (Mouri et al. 2010) and FKBP (Bennett et al. 2002) have been suggested to be involved in memory formation. However, the very similar effects obtained with the two drugs, as well as the literature showing the involvement of calcineurin in other forms of extinction using transgenic inhibition (Baumgärtel et al. 2008) makes it much more likely that our findings are indeed due to inhibition of CaN activity in the brain.

Since CsA and FK-506 injections were performed before the extinction session (as there is no other way to analyze their effects on within-session extinction), one should always consider the possibility of nonspecific pharmacological effects unrelated to memory extinction that could affect the freezing behavior of animals. This is particularly important due to the fact that chronic CsA treatment has been previously shown to cause side effects such as increased anxiety (Sato et al. 2007) and hypolocomotion (Von Hörsten et al. 1998; Sato et al. 2007). However, in our tests in the elevated plus maze, no significant effect of acute CsA injections was found, while treated animals showed a small increase in the distance traveled during open field exploration, arguing against a locomotor or anxiogenic effect as the cause of the increase in freezing at the end of the extinction sessions. Furthermore, no significant difference in behavioral immobility over a 30-min session was observed when animals were conditioned but tested in a different context. Another strong argument against the possibility of a nonspecific effect is the fact that initial freezing levels did not differ between groups at the beginning of the extinction sessions in any of the experiments. Moreover, the possibility that this pattern could be due to an effect being present 90 min but not $60 \mathrm{~min}$ after the injection due to pharmacokinetic reasons is ruled out by the fact that CsA injection $60 \mathrm{~min}$ before conditioning had no effect on freezing $30 \mathrm{~min}$ after training (i.e., 90 min after the injection), as shown in Figure 1C. Taken together, these data corroborate our hypothesis that the effects seen with CsA treatment are indeed due to a modulation of withinsession extinction.

Overall, based on the data presented here, we believe that CaN may be part of a memory labilization system that leads to the rapid modification of behavioral responses during extinction. Other possible components of this system include the CB1 receptor (Plendl and Wotjak 2010) and L-type voltage-gated calcium channels (LVGCCs) (Cain et al. 2002), which have also been shown to be necessary for within-session extinction of fear conditioning. Interestingly, all three of these molecules seem to be specifically involved in extinction, but not in the initial acquisition of fear conditioning (Cain et al. 2002; Marsicano et al. 2002; Baumgärtel et al. 2008; Havekes et al. 2008). The three of them have also been reported to be required for memory destabilization during reconsolidation (Suzuki et al. 2008; Kim et al. 2011; De Oliveira Alvares et al. 2013; Fukushima et al. 2014), along with other mechanisms such as AMPA receptor endocytosis (Hong et al. 2013) and protein degradation through the ubiquitin-proteasome system (Lee 2008; Lee et al. 2008; Sol Fustiñana et al. 2014). This is in line with the view that these molecular components could be part of a system involved in the labilization of synaptic plasticity established by consolidation of the original memory trace (Almeida-Corrêa and Amaral 2014).

In this sense, it is interesting to speculate on which synaptic processes these molecular mechanisms might be regulating. Some studies have mentioned the possible involvement of calcineurin, CB1 receptors, and LVGCCs with LTP reversal or depotentiation (Christie et al. 1997; Zhuo et al. 1999; Gerdeman et al. 2002; Jouvenceau et al. 2003; Lin et al. 2003b). Interestingly, all three mechanisms seem to interact in endocannabinoid-mediated LTD in the hippocampus, with calcineurin apparently integrating the postsynaptic activation signal provided by LVGCCs and the presynaptic signal mediated by CB1 receptors (Heifets et al. 2008). Calcineurin has also been shown to activate downstream targets that can mediate synaptic depression phenomena, such as AMPA receptor endocytosis (Beattie et al. 2000; Kim et al. 2007) and protein degradation through the ubiquitin-proteasome system (Fukushima et al. 2014). Notably, both of these 
targets have also been implicated in memory destabilization during reconsolidation (Lee et al. 2008; Hong et al. 2013) and in extinction (Kim et al. 2007; Dalton et al. 2008; Lee et al. 2008), suggesting that this memory labilization system might mediate both the labilization component of reconsolidation and the within-session component of memory extinction.

Taken together, the data presented here argue in favor of viewing memory extinction as the result of at least two separate, and partially independent, physiological processes, as previously suggested by other authors (Barad 2006; Plendl and Wotjak 2010; Riebe et al. 2012). We believe that such a framework can help to solve some of the divergences in the existing extinction literature, such as the conflicting results concerning the dependence of this process on protein synthesis (Berman and Dudai 2001; Lattal and Abel 2001; Vianna et al. 2001; Lattal et al. 2004). Furthermore, the detailed understanding of these different components of extinction can contribute to the development of more effective ways to modulate this process for the treatment of anxiety disorders, as they might comprise distinct targets for exposure-based therapies, as well as for the pharmacological and/or behavioral potentiation of their effects.

\section{Materials and Methods}

\section{Animals}

Experiments were performed on male Swiss Webster mice aged 812 wk, provided by the Federal University of Rio de Janeiro (UFRJ) and the Oswaldo Cruz Foundation (FIOCRUZ), Rio de Janeiro, Brazil. The animals were housed in groups of up to five per cage, kept on a $12 \mathrm{~h}$ light-dark cycle (lights on at 6 a.m.), and received food and water ad libitum. All procedures were approved by the Institutional Ethical Committee for the Care and Use of Laboratory Animals of the Federal University of Rio de Janeiro (CEUA-CCS IBQM046 and CEUA-CCS 175/13) in compliance with the Brazilian Ethical Committee of the Use of Animals in Science (CONCEA) and US National Institute of Health (NIH) guidelines.

\section{Drugs}

The protein synthesis inhibitor cycloheximide (CHX; Fluka Analytical/Sigma-Aldrich) was dissolved in 0.9\% saline and injected intraperitoneally (i.p.; $100 \mathrm{mg} / \mathrm{kg}$ ) or intracerebroventricularly (i.c.v.; $55 \mu \mathrm{g} / 3 \mu \mathrm{L} / \mathrm{mouse}$ ). The calcineurin activity inhibitor cyclosporin A (CsA, Sigma-Aldrich or Biomanguinhos) was dissolved in dimethyl sulfoxide $100 \%$ (DMSO, Merck) for i.p. injections $(20 \mathrm{mg} / \mathrm{kg})$ and in $85 \%$ DMSO for i.c.v. injections $(15 \mu \mathrm{g} /$ $\mu \mathrm{L}, 2 \mu \mathrm{L} /$ mouse). Drug samples from the two different sources used had very similar effects in the single-session extinction protocol and were thus pooled together in Figure 2B. The calcineurin activity inhibitor FK-506 (Tacrolimus, Sigma-Aldrich) was dissolved in $100 \%$ DMSO for i.p. injections $(5 \mathrm{mg} / \mathrm{kg})$.

\section{Intracerebroventricular injections (i.c.v.)}

Each animal was anesthetized using inhalational isoflurane (Isoforine, Cristália). Immediately after effective anesthesia was obtained, a $0.33-\mathrm{mm}$ caliber needle was positioned perpendicularly at the midline, at a point equidistant from the animal's eyes and its ears, and lowered $3.5 \mathrm{~mm}$ down (Laursen and Belknap 1986). The needle was connected through polyethylene tubing to a $10-\mu \mathrm{L}$ Hamilton syringe that was used to deliver $3 \mu \mathrm{L}$ (CHX) or $2 \mu \mathrm{L}$ (CsA), or their vehicles gradually for $5 \mathrm{sec}$. After injection, the needle was left in place for an additional 10 sec to avoid reflux. The precision of i.c.v. injections was evaluated after behavioral testing and euthanasia by macroscopically analyzing the injection tract left in the brain. Animals in which the needle mark did not reach the lateral ventricle were excluded from the analyses.

\section{Apparatus}

Fear conditioning was assessed in either one of two chambers. The first, used for contextual fear conditioning, was a rectangular chamber $(14 \times 25,25 \mathrm{~cm}$ high) with aluminum side walls and a front wall and ceiling door made of plexiglass; its grid floor, made of stainless-steel bars (spaced $12.5 \mathrm{~mm}$ ), was connected to a circuit board and a shock generator that could deliver electrical footshocks (Insight Ltd). The second, used for auditory fear conditioning, was a square chamber $(25 \times 25,25 \mathrm{~cm}$ high $)$ made of black methacrylate, with a plexiglass front wall; its stainless-steel grid floor and ceiling speakers were connected to a computercontrolled shock and sound generator system (Panlab/Harvard Apparatus). For testing in a different context after tone conditioning, its shape and color were modified by adding hard plastic white walls, an acrylic cylinder (20 cm diameter), and a plain metal coverage on its grid floor. For testing in a different context after contextual fear conditioning, the same acrylic cylinder was used but with a distinct floor and lowered room lighting as well. In addition to these visual elements, the odor was also modified between contexts. While the training context was sanitized with $70 \%$ ethanol after removal of each animal, the testing context was cleaned with a mixture of disinfectant (eucalyptus scent) and $70 \%$ ethanol at a ratio of $1: 1$.

\section{General procedures and data collection}

For $2 \mathrm{~d}$ before the behavioral experiments, animals were weighed, had their tails marked for identification and were handled for $\sim 2$ min each to become used to contact with the experimenters. Behavioral testing was carried out during the diurnal phase (8 a.m.-5 p.m.). On days when the behavioral tasks were performed, animals were transferred to the testing room at least $60 \mathrm{~min}$ before the start of the session. Light, temperature and room noise were controlled. Freezing behavior was defined as the total absence of body and head movements, except those associated with breathing and/or tail shaking, and was quantified by a trained observer blind to the experimental groups, using a stopwatch. Freezing measurements were expressed as a percentage of total session time. All sessions were filmed to allow later analysis of freezing behavior.

\section{Contextual fear conditioning}

The training session (conditioning) consisted of placing the animals in the context, which could be freely explored for $2 \mathrm{~min}$. After this habituation time, animals received two footshocks ( $2 \mathrm{sec}, 0.8 \mathrm{~mA}$ ) with a 30 -sec interval, followed by an additional $60 \mathrm{sec}$ of exploration after the last shock before returning to their home cages. At distinct intervals after the training session, extinction sessions and/or retrieval tests were performed as described below. For extinction experiments, only animals with freezing levels $>5 \%$ during the initial period ( $3 \mathrm{~min}$ ) of the extinction session, indicating minimal learning of the task, were included in the analyses.

\section{Effect of calcineurin and protein synthesis inhibition on fear learning}

In experiments in which this protocol was used, animals received systemic injections of $10 \mathrm{~mL} / \mathrm{kg}$ of CHX $(100 \mathrm{mg} / \mathrm{kg})$ or its vehicle (0.9\% saline) ( $n=15-18) 30 \mathrm{~min}$ before the conditioning session, or of $2.5 \mathrm{~mL} / \mathrm{kg} \mathrm{CsA}(20 \mathrm{mg} / \mathrm{kg})$ or its vehicle (DMSO) $(n=15-16)$ $60 \mathrm{~min}$ before this session. Twenty-four hours after the training session the animals returned to the conditioning context for a 3-min test session with no shock, in which freezing time was recorded and used as a memory index. Two additional groups of animals treated with $2.5 \mathrm{~mL} / \mathrm{kg}$ CsA $(20 \mathrm{mg} / \mathrm{kg})$ or its vehicle (DMSO) $(n=11-13) 60$ min before training received a similar training session but were tested $30 \mathrm{~min}$ after the end of the session. 


\section{Effect of calcineurin inhibition on single-session contextual fear extinction}

Animals were trained without pharmacological treatment according to the protocol described above. Twenty-four hours later, they were divided into the experimental groups and received injections of $2.5 \mathrm{~mL} / \mathrm{kg}$ of CsA $(20 \mathrm{mg} / \mathrm{kg}$ ) (two experiments with CsA from different suppliers, $n=9-12$ each), $2.5 \mathrm{~mL} / \mathrm{kg}$ of FK-506 (5 mg/ $\mathrm{kg})(n=9)$, or their vehicle (DMSO) $60 \mathrm{~min}(n=6-12$ for each experiment) before the extinction session. The extinction session consisted of a reexposure to the conditioning context for 30 min with no shock. Twenty-four hours after the extinction session, animals returned once more to the context for a 3-min test session to assess between-session extinction.

\section{Effect of intracerebroventricular inhibition of calcineurin or protein synthesis on contextual fear extinction}

Animals were initially trained as described in previous protocols. Twenty-four hours later, they received i.c.v. injections of CsA $(n=7)$, CHX $(n=8)$ or their respective vehicles $(85 \%$ DMSO or $0.9 \%$ saline, $n=9$ in each experiment), following the protocol previously described. Sixty minutes after the injection, mice underwent a 30-min extinction session (as described above). Twenty-four hours after the extinction session, they were reexposed to the context for a 3-min test session.

\section{Effect of calcineurin inhibition on multiple-session contextual fear extinction}

Animals were initially trained as previously described. Over the following days, they underwent either three daily 10-min extinction sessions ( $n=11-12$ /group) or six daily 5-min extinction sessions ( $n=5-7$ /group), consisting of reexposure to the context without shock or other stimuli). Sixty minutes before each session, they were given i.p. injections of $2.5 \mathrm{~mL} / \mathrm{kg}$ of CsA $(20 \mathrm{mg} / \mathrm{kg}$ ) or DMSO. Twenty-four hours after the last extinction session, the animals returned to the experimental context for a 3-min test session without pharmacological treatment.

\section{Effect of calcineurin inhibition on auditory fear extinction}

In the training session, animals were placed in the conditioning context (context A) and could explore it freely for $3 \mathrm{~min}$. After this initial period, they heard three tones $(100 \mathrm{~dB}, 1 \mathrm{kHz}, 20 \mathrm{sec}$ each) that coterminated with footshocks $(0.6 \mathrm{~mA}, 2 \mathrm{sec})$. The tones were separated by fixed intervals of $30 \mathrm{sec}$. After the last tone, animals remained in the box for $60 \mathrm{sec}$ before returning to their home cages. Twenty-four hours after training, the animals underwent an extinction session in a different context (context B), which was a modification of the original one with the addition of some elements (see Apparatus).

Twenty-four hours after conditioning, mice received systemic injections of $2.5 \mathrm{~mL} / \mathrm{kg}$ of CsA $(20 \mathrm{mg} / \mathrm{kg})$ or its vehicle (DMSO). Sixty minutes later, they underwent an extinction session in context B according to one of two protocols. For singletone extinction ( $n=8 /$ group), animals were placed in the context and after $3 \mathrm{~min}$ of free exploration heard a single 3-min long unpaired tone $(100 \mathrm{~dB}, 1 \mathrm{kHz})$. For multiple-tone extinction, animals ( $n=10 /$ group) were placed in the context and after 3 min heard thirty 20 -sec long unpaired tones $(100 \mathrm{~dB}, 1 \mathrm{kHz}, 20 \mathrm{sec})$, separated by variable intervals of 5-20 sec. Sixty seconds after the extinction protocol, animals were placed back in their home cages. In the single-tone protocol, animals' freezing behavior was measured for 3 min before the tone, throughout the duration of the tone (which was divided into 60-sec intervals for analysis), and for $1 \mathrm{~min}$ after the tone. In the multiple-tone protocol, freezing was measured throughout the duration of each tone, with tones grouped into blocks of three for analysis.

Twenty-four hours after extinction, animals were reexposed to context B for a test session, which consisted of 3 min of exploration followed by three unpaired tones $(100 \mathrm{~dB}, 1 \mathrm{kHz}, 20 \mathrm{sec}$ each), with 30-sec intervals, and an additional $60 \mathrm{sec}$ on the chamber after the tone, with freezing levels measured during the tones.

\section{Elevated plus maze}

The maze was made of liquid-impervious laminated wood (closed arms) and acrylic (open arms) and consisted of four $30 \mathrm{~cm} \times 6 \mathrm{~cm}$ arms that were elevated $50 \mathrm{~cm}$ above the floor. The closed arms had $15-\mathrm{cm}$ high walls, while the open arms had $0.5-\mathrm{cm}$ side edges and a $1-\mathrm{cm}$ front edge to prevent the animals from slipping. A central area of $5 \times 5 \mathrm{~cm}$ was considered neutral area and was the starting point of the animals. Animals ( $n=12 /$ group) were positioned in the neutral zone, $60 \mathrm{~min}$ after systemic injection of CsA $(20 \mathrm{mg} / \mathrm{kg})$ or vehicle (DMSO), and could freely explore the maze for $5 \mathrm{~min}$. The maze surface was cleaned with ethanol $70 \%$ between test sessions to avoid remaining odours from previously tested animals. The behavior of animals was analyzed by the absolute time spent and number of entries into the open arms, both of which are negatively correlated with anxiety. An arm entry was counted after the animal crossed the neutral area borders with all four paws.

\section{Open field exploration}

Sixty minutes after systemic injections of $2.5 \mathrm{~mL} / \mathrm{kg} \mathrm{CsA}(20 \mathrm{mg} /$ $\mathrm{kg})$ or vehicle, animals $(n=20-21$; two similar experiments pooled) were placed into a black wooden box $(30 \times 30 \times 30 \mathrm{~cm})$ to freely explore it for $10 \mathrm{~min}$. The sessions were recorded with a webcam and locomotion during the task was calculated automatically using the MouseTracker software (Tort et al. 2006).

\section{Exposure to a novel context}

One day after contextual conditioning (as previously described) animals (three pooled experiments, $n=25-27$ ) received injections of $2.5 \mathrm{~mL} / \mathrm{kg}$ of CsA $(20 \mathrm{mg} / \mathrm{kg}$ ) or DMSO $60 \mathrm{~min}$ before a 30-min exposure session to a novel context. This session consisted in a simple presentation of a novel context (a transparent glass cylinder with a $20-\mathrm{cm}$ diameter, placed in a new experimental room), which the animals could freely explore for $30 \mathrm{~min}$, without any further stimuli. Immobility behavior (consisting either of freezing or sleeping behavior) was measured throughout the session.

\section{Statistical analysis}

Data from all experiments were analyzed in GraphPad Prism 6.0. Comparisons between groups were performed using Student's $t$ test (with or without Welch's correction, depending on the difference between variances in each experiment), for comparisons involving a single test session. Two-way repeated-measures ANOVA was used for experiments involving multiple comparisons of freezing at different times, with time and treatment as independent variables and post hoc Bonferroni tests for comparison between groups at specific times. This kind of analysis was used to evaluate within-session extinction (using multiple time points throughout the duration of the extinction sessions) as well as between-session extinction (using the beginning of the extinction session and the test session as the two time points).

Pearson's correlation coefficient was used to compare the data of individual animals on short- and long-term extinction (Fig. 2D,E). For the statistical power calculations concerning the experiment in Figure 6D, we used the mean difference in freezing levels between groups in Figure 2B (i.e., a 94\% increase in freezing levels in the CsA group) as the difference to be detected by the experiment, and the sample size, standard deviation and withinanimal correlation values observed in the experiment in Figure $6 \mathrm{D}$ as input parameters. Power calculations were performed using G*Power 3.1 (Faul et al. 2007).

$P$ values $<0.05$ were considered statistically significant in all experiments. All results are expressed as mean \pm standard error of the mean (SEM). 


\section{Acknowledgments}

This work was supported by grants by FAPERJ (E-26/110.918/ 2009), CNPq (474434/2010-9 and 478904/2012-6), and PR-2/ UFRJ (ALV 2011 Prize), Brazil to O.B.A., and performed in the behavioral facilities provided by the National Center for Bioimaging (CENABIO). S.A.-C., T.C.M., C.F.D.C., M.M.C.G., and L.S.J. received scholarships from CNPq, FAPERJ, and PIBIC-UFRJ. We thank Fernanda Tubenchlak, Mateus Perissé, and Charles Vargas-Lopes for assisting in selected experiments, and Drs Sérgio Ferreira, Fernanda de Felice, Rogério Panizzutti, Jean-Christophe Houzel, and Gilda Neves for use of their laboratories.

\section{References}

Almeida-Corrêa S, Amaral OB. 2014. Memory labilization in reconsolidation and extinction-Evidence for a common plasticity system? J Physiol Paris 108: 292-306.

Barad M. 2006. Is extinction of fear erasure or inhibition? Why both, of course. Learn Mem 13: 108-109.

Baumgärtel K, Genoux D, Welzl H, Tweedie-Cullen RY, Koshibu K, Livingstone-Zatchej M, Mamie C, Mansuy IM. 2008. Control of the establishment of aversive memory by calcineurin and Zif268. Nat Neurosci 11: 572-578.

Beattie EC, Carroll RC, Yu X, Morishita W, Yasuda H, von Zastrow M, Malenka RC. 2000. Regulation of AMPA receptor endocytosis by a signaling mechanism shared with LTD. Nat Neurosci 3: $1291-1300$

Bennett PC, Schmidt L, Lawen A, Moutsoulas P, Ng KT. 2002. Cyclosporin A, FK506 and rapamycin produce multiple, temporally distinct, effects on memory following single-trial, passive avoidance training in the chick. Brain Res 927: 180-194.

Berman DE, Dudai Y. 2001. Memory extinction, learning anew, and learning the new: dissociations in the molecular machinery of learning in cortex. Science 291: 2417-2419.

Bram RJ, Hung DT, Martin PK, Schreiber SL, Crabtree GR. 1993. Identification of the immunophilins capable of mediating inhibition of signal transduction by cyclosporin A and FK506: roles of calcineurin binding and cellular location. Mol Cell Biol 13: $4760-4769$.

Cain CK, Blouin AM, Barad M. 2002. L-type voltage-gated calcium channels are required for extinction, but not for acquisition or expression, of conditional fear in mice. J Neurosci 22: 9113-9121.

Christie BR, Schexnayder LK, Johnston D. 1997. Contribution of voltage-gated $\mathrm{Ca}^{2+}$ channels to homosynaptic long-term depression in the CA1 region in vitro. J Neurophysiol 77: 1651-1655.

Dalton GL, Wang YT, Floresco SB, Phillips AG. 2008. Disruption of AMPA receptor endocytosis impairs the extinction, but not acquisition of learned fear. Neuropsychopharmacology 33: 2416-2426.

Davis M. 2011. NMDA receptors and fear extinction: implications for cognitive behavioral therapy. Dialogues Clin Neurosci 13: 463-474

de la Fuente V, Freudenthal R, Romano A. 2011. Reconsolidation or extinction: transcription factor switch in the determination of memory course after retrieval. J Neurosci 31: 5562-5573.

de la Fuente V, Federman N, Fustiñana MS, Zalcman G, Romano A. 2014 Calcineurin phosphatase as a negative regulator of fear memory in hippocampus: control on nuclear factor- $\mathrm{\kappa}$ signaling in consolidation and reconsolidation. Hippocampus 24: 1549-1561.

De Oliveira Alvares L, Crestani AP, Cassini LF, Haubrich J, Santana F, Quillfeldt JA. 2013. Reactivation enables memory updating, precision-keeping and strengthening: exploring the possible biological roles of reconsolidation. Neuroscience 244: 42-48.

Eisenberg M, Kobilo T, Berman DE, Dudai Y. 2003. Stability of retrieved memory: inverse correlation with trace dominance. Science 301: 1102-1104.

Faul F, Erdfelder E, Lang AG, Buchner A. 2007. G*Power 3: a flexible statistical power analysis program for the social, behavioral, and biomedical sciences. Behav Res Methods 39: 175-191.

Fukushima H, Zhang Y, Archbold G, Ishikawa R, Nader K, Kida S. 2014. Enhancement of fear memory by retrieval through reconsolidation. Elife 3: e02736.

Gerdeman GL, Ronesi J, Lovinger DM. 2002. Postsynaptic endocannabinoid release is critical to long-term depression in the striatum. Nat Neurosci 5: 446-451.

Havekes R, Nijholt IM, Visser AK, Eisel UL, Van der Zee EA. 2008. Transgenic inhibition of neuronal calcineurin activity in the forebrain facilitates fear conditioning, but inhibits the extinction of contextual fear memories. Neurobiol Learn Mem 89: 595-598.
Heifets BD, Chevaleyre V, Castillo PE. 2008. Interneuron activity controls endocannabinoid-mediated presynaptic plasticity through calcineurin. Proc Natl Acad Sci 105: 10250-10255.

Hernandez PJ, Abel T. 2008. The role of protein synthesis in memory consolidation: progress amid decades of debate. Neurobiol Learn Mem 89: $293-311$.

Hong I, Kim J, Kim J, Lee S, Ko HG, Nader K, Kaang BK, Tsien RW, Choi S. 2013. AMPA receptor exchange underlies transient memory destabilization on retrieval. Proc Natl Acad Sci 110: $8218-8223$.

Huai Q, Kim HY, Liu Y, Zhao Y, Mondragon A, Liu JO, Ke H. 2002. Crystal structure of calcineurin-cyclophilin-cyclosporin shows common but distinct recognition of immunophilin-drug complexes. Proc Natl Acad Sci 99: 12037-12042.

Ikegami S, Inokuchi K. 2000. Antisense DNA against calcineurin facilitates memory in contextual fear conditioning by lowering the threshold for hippocampal long-term potentiation induction. Neuroscience $\mathbf{9 8 :}$ 637-646.

Izquierdo I, Barros DM, Mello e Souza T, de Souza MM, Izquierdo LA, Medina JH. 1998. Mechanisms for memory types differ. Nature 393: $635-636$.

Jouvenceau A, Billard JM, Haditsch U, Mansuy IM, Dutar P. 2003. Different phosphatase-dependent mechanisms mediate long-term depression and depotentiation of long-term potentiation in mouse hippocampal CA1 area. Eur J Neurosci 18: 1279-1285.

Kim JJ, Fanselow MS. 1992. Modality-specific retrograde amnesia of fear. Science 256: $675-677$

Kim J, Lee S, Park K, Hong I, Song B, Son G, Park H, Kim WR, Park E, Choe HK, et al. 2007. Amygdala depotentiation and fear extinction. Proc Natl Acad Sci 104: 20955-20960.

Kim R, Moki R, Kida S. 2011. Molecular mechanisms for the destabilization and restabilization of reactivated spatial memory in the Morris water maze. Mol Brain 4: 9 .

Kissinger CR, Parge HE, Knighton DR, Lewis CT, Pelletier LA, Tempczyk A, Kalish VJ, Tucker KD, Showalter RE, Moomaw EW, et al. 1995. Crystal structures of human calcineurin and the human FKBP12-FK506-calcineurin complex. Nature 378: 641-644.

Lattal KM, Abel T. 2001. Different requirements for protein synthesis in acquisition and extinction of spatial preferences and context-evoked fear. J Neurosci 21: 5773-5780.

Lattal KM, Honarvar S, Abel T. 2004. Effects of post-session injections of anisomycin on the extinction of a spatial preference and on the acquisition of a spatial reversal preference. Behav Brain Res 153: 327-339.

Laursen SE, Belknap JK. 1986. Intracerebroventricular injections in mice. Some methodological refinements. J Pharmacol Methods 16: $355-357$.

Lee JL. 2008. Memory reconsolidation mediates the strengthening of memories by additional learning. Nat Neurosci 11: 1264-1266.

Lee JL, Flavell CR. 2014. Inhibition and enhancement of contextual fear memory destabilization. Front Behav Neurosci 8: 144.

Lee SH, Choi JH, Lee N, Lee HR, Kim JI, Yu NK, Choi SL, Lee SH, Kim H, Kaang BK. 2008. Synaptic protein degradation underlies destabilization of retrieved fear memory. Science 319: 1253-1256.

Lin CH, Yeh SH, Leu TH, Chang WC, Wang ST, Gean PW. 2003a. Identification of calcineurin as a key signal in the extinction of fear memory. J Neurosci 23: $1574-1579$.

Lin CH, Lee CC, Gean PW. 2003b. Involvement of a calcineurin cascade in amygdala depotentiation and quenching of fear memory. $\mathrm{Mol}$ Pharmacol 63: $44-52$

Liu J, Farmer JD Jr, Lane WS, Friedman J, Weissman I, Schreiber SL. 1991. Calcineurin is a common target of cyclophilin-cyclosporin A and FKBP-FK506 complexes. Cell 66: 807-815.

Malleret G, Haditsch U, Genoux D, Jones MW, Bliss TV, Vanhoose AM, Weitlauf C, Kandel ER, Winder DG, Mansuy IM. 2001. Inducible and reversible enhancement of learning, memory, and long-term potentiation by genetic inhibition of calcineurin. Cell 104: 675-686.

Maren S. 2011. Seeking a spotless mind: extinction, deconsolidation, and erasure of fear memory. Neuron 70: $830-845$.

Marsicano G, Wotjak CT, Azad SC, Bisogno T, Rammes G, Cascio MG Hermann H, Tang J, Hofmann C, Zieglgansberger W, et al. 2002. The endogenous cannabinoid system controls extinction of aversive memories. Nature 418: 530-534.

Merlo E, Milton AL, Goozée ZY, Theobald DE, Everitt BJ. 2014. Reconsolidation and extinction are dissociable and mutually exclusive processes: behavioral and molecular evidence. J Neurosci 34: $2422-2431$.

Mouri A, Noda Y, Shimizu S, Tsujimoto Y, Nabeshima T. 2010. The role of cyclophilin D in learning and memory. Hippocampus 20: 293-304.

Nader K, Schafe GE, Le Doux JE. 2000. Fear memories require protein synthesis in the amygdala for reconsolidation after retrieval. Nature 406: $722-726$. 
Osan R, Tort AB, Amaral OB. 2011. A mismatch-based model for memory reconsolidation and extinction in attractor networks. PLoS One 6: e23113.

Pavlov IP. 1927. Conditioned reflexes: an investigation of the physiological activity of the cerebral cortex. Oxford University Press, London.

Pedreira ME, Maldonado H. 2003. Protein synthesis subserves reconsolidation or extinction depending on reminder duration. Neuron 38: $863-869$.

Plendl W, Wotjak CT. 2010. Dissociation of within- and between-session extinction of conditioned fear. J Neurosci 30: 4990-4998.

Riebe CJ, Pamplona FA, Kamprath K, Wotjak CT. 2012. Fear relief-toward a new conceptual frame work and what endocannabinoids gotta do with it. Neuroscience 204: $159-185$.

Sato Y, Takayanagi Y, Onaka T, Kobayashi E. 2007. Impact of cyclosporine upon emotional and social behavior in mice. Transplantation 83: $1365-1370$.

Schreiber SL. 1991. Chemistry and biology of the immunophilins and their immunosuppressive ligands. Science 251: 283-287.

Sol Fustiñana M, de la Fuente V, Federman N, Freudenthal R, Romano A. 2014. Protein degradation by ubiquitin-proteasome system in formation and labilization of contextual conditioning memory. Learn Mem 21: 478-487.

Suzuki A, Josselyn SA, Frankland PW, Masushige S, Silva AJ, Kida S. 2004. Memory reconsolidation and extinction have distinct temporal and biochemical signatures. J Neurosci 24: 4787-4795.

Suzuki A, Mukawa T, Tsukagoshi A, Frankland PW, Kida S. 2008. Activation of LVGCCs and CB1 receptors required for destabilization of reactivated contextual fear memories. Learn Mem 15: 426-433.
Szapiro G, Vianna MR, McGaugh JL, Medina JH, Izquierdo I. 2003. The role of NMDA glutamate receptors, PKA, MAPK, and CAMKII in the hippocampus in extinction of conditioned fear. Hippocampus 13: 53-58.

Tort AB, Neto WP, Amaral OB, Kazlauckas V, Souza DO, Lara DR. 2006. A simple webcam-based approach for the measurement of rodent locomotion and other behavioural parameters. J Neurosci Methods 157: 91-97.

Vianna MR, Szapiro G, McGaugh JL, Medina JH, Izquierdo I. 2001. Retrieval of memory for fear-motivated training initiates extinction requiring protein synthesis in the rat hippocampus. Proc Natl Acad Sci 98: $12251-12254$.

Von Hörsten S, Exton MS, Vöge J, Schult M, Nagel E, Schmidt RE, Westermann J, Schedlowski M. 1998. Cyclosporine A affects open field behavior in DA rats. Pharmacol Biochem Behav 60: 71-76.

Zeng H, Chattarji S, Barbarosie M, Rondi-Reig L, Philpot BD, Miyakawa T, Bear MF, Tonegawa S. 2001. Forebrain-specific calcineurin knockout selectively impairs bidirectional synaptic plasticity and working/ episodic-like memory. Cell 107: 617-629.

Zhuo M, Zhang W, Son H, Mansuy I, Sobel RA, Seidman J, Kandel ER. 1999. A selective role of calcineurin A $\alpha$ in synaptic depotentiation in hippocampus. Proc Natl Acad Sci 96: 4650-4655.

Received December 3, 2014; accepted in revised form January 2, 2015. 


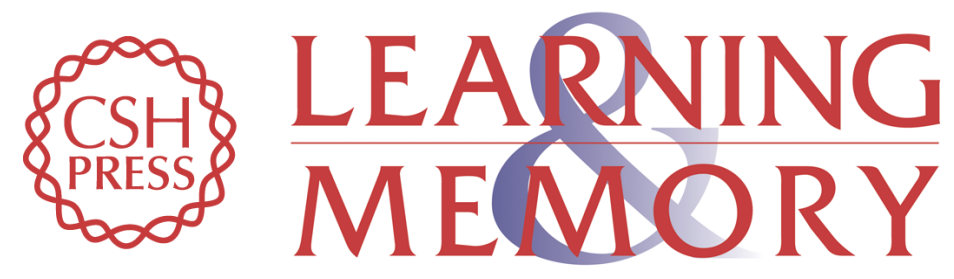

\title{
Calcineurin inhibition blocks within-, but not between-session fear extinction in mice
}

\author{
Suellen Almeida-Corrêa, Thiago C. Moulin, Clarissa F. D. Carneiro, et al.
}

Learn. Mem. 2015, 22:

Access the most recent version at doi:10.1101/Im.037770.114

\begin{aligned} & \hline References $\begin{array}{l}\text { This article cites } 60 \text { articles, } 23 \text { of which can be accessed free at: } \\ \text { http://learnmem.cshlp.org/content/22/3/159.full.html\#ref-list-1 }\end{array} \\ & \begin{array}{c}\text { Creative } \\ \text { Commons } \\ \text { License }\end{array} \begin{array}{l}\text { This article is distributed exclusively by Cold Spring Harbor Laboratory Press for the } \\ \text { first } 12 \text { months after the full-issue publication date (see } \\ \text { http://learnmem.cshlp.org/site/misc/terms.xhtml). After } 12 \text { months, it is available under } \\ \text { a Creative Commons License (Attribution-NonCommercial } 4.0 \text { International), as } \\ \text { described at http://creativecommons.org/licenses/by-nc/4.0/. } \\ \text { Receive free email alerts when new articles cite this article - sign up in the box at the } \\ \text { Service } \\ \text { top right corner of the article or click here. }\end{array} \\ &$\hline\end{aligned}

